\title{
A new rapid Stability indicating RP-PDA-UPLC method for the estimation of Assay of Pemetrexed disodium-An anti-Lung cancer drug from lyophilized parenteral formulation
}

\author{
Vamsi Krishna Galla, V. Archana, Rajeswari Jinka* \\ Department of Biochemistry, Acharya Nagarjuna University, Guntur, Andhra Pradesh, India.
}

\begin{tabular}{|c|c|}
\hline ARTICLE INFO & ABSTRACT \\
\hline $\begin{array}{l}\text { Article history: } \\
\text { Received on: } 28 / 05 / 2017 \\
\text { Accepted on: } 18 / 08 / 2017 \\
\text { Available online: } 30 / 10 / 2017\end{array}$ & $\begin{array}{l}\text { A new rapid stability-indicating reversed phase ultra-performance liquid chromatographic (RP-UPLC) method } \\
\text { with a linear gradient and shortest run time of } 4.0 \text { minutes is developed for the determination of assay of } \\
\text { pemetrexed disodium, an anti-cancer drug from its lyophilized parenteral formulation. The method is developed } \\
\text { on Waters binary UPLC, equipped with Aquity BEH C } 18 \text { column and system set with mobile phase A as } 0.1 \%\end{array}$ \\
\hline $\begin{array}{l}\text { Key words: } \\
\text { Pemetrexed, UPLC, Aquity } \\
\text { BEH C18, Forced } \\
\text { degradation, Peak purity, } \\
\text { Photo diode array (PDA), } \\
\text { Method validation. }\end{array}$ & $\begin{array}{l}\text { peroxide, acid, base, hydrolytic, thermal, and photolytic degradation, within which major degradants were } \\
\text { observed in acid stress at } 1 \mathrm{~N} \mathrm{HCl} 60^{\circ} \mathrm{C} \text { and } 3 \% \text { peroxide stress at room temperature. Pemetrexed (main peak) } \\
\text { and its degradant peaks were well separated and were monitored at UV-230nm. Evaluation of spectral purity for } \\
\text { main component is performed using PDA (photo diode array) in presence of its degradants formed during stress } \\
\text { studies, which assures the stability indicating capability of the method. \% RSD for mean of precision and } \\
\text { accuracy at } 3 \text { different levels ranging from } 50 \text { to } 150 \% \text { were within limits and coefficient of correlation found > } \\
0.999 \text { for linearity. The newly developed UPLC assay method is fully validated and found to be specific, } \\
\text { Robust, Precise, Linear and Accurate in determining assay of Pemetrexed from drug product as per ICH } \\
\text { guidelines. }\end{array}$ \\
\hline
\end{tabular}

\section{INTRODUCTION}

Non-small cell lung cancer (NSCLC) accounts for about $85 \%$ of all lung cancers cases and is considered as leading cause of cancer death in the United States and worldwide. It is also sub classified as squamous $(\sim 30 \%)$ or non-squamous $(\sim 70 \%)$ which includes adeno carcinoma and large cell histologies types. NSCLC is a particularly aggressive form of lung cancer, for which there is a lack of effective and welltolerated treatments available. (Julian et al., 2008) Although new cytotoxic agents and targeted therapies were evaluated, but their efficacy is limited for first-line therapy of NSCLC. Based on recent advances in clinical trials and results of the phase III

\footnotetext{
* Corresponding Author

Dr. J. Rajeswari, Assistant Professor, Department of Biochemistry, Acharya Nagarjuna University, Nagarjuna Nagar, Guntur, Andhra Pradesh 522510, India. Email: jinkarajeswari @ gmail.com.
}

studies, pemetrexed an multi-targeted antifolate drug progressively became one of the most frequently used cytotoxic chemotherapy agents for treating stage IV nonsquamous NSCLC (Hanauske et al., 2001, Pascale et al., 2016). Pemetrexed is approved by the Food and Drug Association (FDA) for several steps of nonsquamous NSCLC treatment (first line, maintenance therapy, and second and third lines). Pemetrexed is indicated as a singleagent for the treatment of patients with locally advanced or metastatic nonsquamous non-small cell lung cancer after prior chemotherapy. Pemetrexed, in combination with cisplatin is also indicated for the treatment of patients with malignant pleural mesothelioma whose disease is unresectable or who are otherwise not candidates for curative surgery (Adjei et al., 2003). Pemetrexed disodium heptahydrate has the chemical name L-Glutamic acid,N[4-[2 -(2-amino-4,7-dihydro-4-oxo1H-pyrrolo[2,3-d]pyrimidin-5yl)ethyl]benzoyl]-, disodium salt, heptahydrate with a molecular formula of $\mathrm{C}_{20} \mathrm{H}_{19} \mathrm{~N}_{5} \mathrm{Na}_{2} \mathrm{O}_{6} 7 \mathrm{H}_{2} \mathrm{O}$ and a molecular weight of 597.49 amu (Figure-1). 
The drug product is supplied as a sterile lyophilized powder for intravenous infusion available in single-dose vials in two strengths of $100-\mathrm{mg}$ and 500-mg along with mannitol at approximately $1: 1$ ratio. (http://www.rxlist.com/alimta-drug.htm [Accessed on 02-03-2017].

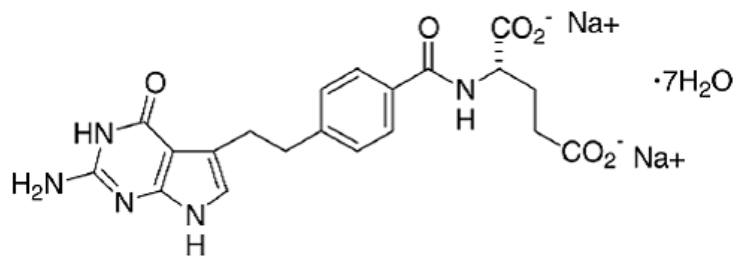

Fig. 1: Chemical Structure of Pemetrexed Disodium.

According to literature survey, few methods were reported about evaluation of assay of pemetrexed and its stability in solutions by HPLC (Saravanan et al., 2007), (Banu et al., 2010), (Rondelot et al., 2007), (Zhang et al., 2006). Few methods describe about LC-MS studies of pemetrexed and its metabolites in biological fluids like plasma and urine (Roland et al., 2010), (Meesters et al., 2010), (Li Wang et al., 2006) (Rivory et al., 2001). Recently, UPLC which works on sub- $2 \mu$ particle size packed columns became a novel technique in industrial research and quality control sectors, ensuring faster and adequate analytical output without compromising quality of analysis, eventually improving productivity (Mazzeo et al., 2005, Wren et al., 2006, Nguyen et al., 2006, Villiers et al., 2006, Russo et al., 2008). Over past few years, analytical research works and publications on UPLC were tremendously increasing, and hence the technique is chosen for current work. As per literature survey, no RP-UPLC assay method is available with shortest run time, which established stress studies of Pemetrexed drug product along with spectral purity (PDA) analysis with negligible carry over. Analytical procedure for assay for this molecule is currently not listed in any official pharmacopeia and this will be first of kind on UPLC. The newly developed method is fully validated in terms of specificity, precision, accuracy, linearity, ruggedness and robustness as per ICH and regulatory guidelines (Q2 (R1), 2005).

\section{MATERIALS AND METHODS}

\section{Chemicals and reagents}

HPLC gradient grade $(0.2 \mu$ Filtered) acetonitrile, HPLC grade water and ortho-phosphoric acid (85\%) is procured from Thermo Fisher suppliers, Hyderabad. Pemetrexed disodium standard is received as research sample from Department of Biochemistry, Acharya Nagarjuna University, Guntur, Andhra Pradesh. Drug product (Strength 100mg/vial) is purchased from MDC-NIMS, Hyderabad. Mannitol, as a placebo constituent is procured from alfa aesar Ltd, Hyderabad.

\section{Equipments}

Chromatographic conditions of the developed method is optimized on Acquity UPLC ${ }^{\mathrm{TM}}$ binary system (Waters, Milford,
USA) equipped with a sample manager and a photodiode array (PDA) detector. Chromatograms and spectral data is monitored, integrated and processed using empower-2 software. Photo stability chamber (Sanyo, Leicestershire, UK), Dry air oven (Cintex, Mumbai, India), Digital water bath (Thermo Scientifics, USA), were used to achieve respective photolytic, thermal, acid and alkali stress conditions. Ultra sonication (Power sonic 420, Labtech, Korea) is utilized during degassing of Mobile phases and preparation of Solutions.

\section{Chromatographic Conditions}

Refer Table-1 for chromatographic conditions implemented for the current study. $0.2 \mu \mathrm{m}$ membrane filtered HPLC water is used during mobile phase preparation. Sample manager is set with $10 \mu \mathrm{L}$ loop and characterized seal and loop volume before start.

Pemetrexed and its degradants peaks were monitored at UV-wavelength of $230 \mathrm{~nm}$, with sampling rate of $10 \mathrm{point} / \mathrm{sec}, 1.2$ $\mathrm{nm}$ resolution.

Table 1: UPLC chromatographic conditions.

\begin{tabular}{|c|c|c|c|}
\hline Column & \multicolumn{3}{|c|}{ Aquity BEH C18, $100 \times 2.1 \mathrm{~mm}, 1.7 \mu \mathrm{m}$} \\
\hline 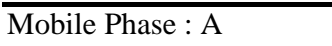 & \multicolumn{3}{|c|}{$0.1 \%$ Ortho- Phosphoric Acid in Water } \\
\hline Mobile Phase : B & \multicolumn{3}{|l|}{ Acetonitrile } \\
\hline Flow rate & \multicolumn{3}{|l|}{$0.3 \mathrm{~mL} / \mathrm{min}$} \\
\hline Column oven temperature & \multicolumn{3}{|l|}{$40^{\circ} \mathrm{C}$} \\
\hline Sample temperature & \multicolumn{3}{|l|}{$25^{\circ} \mathrm{C}$} \\
\hline Injection Volume & \multicolumn{3}{|l|}{$4 \mu \mathrm{L}$} \\
\hline Strong needle wash & \multicolumn{3}{|c|}{ 10:90v/v Water: acetonitrile, $500 \mu \mathrm{L}$} \\
\hline Weak needle wash & \multicolumn{3}{|c|}{$90: 10 \mathrm{v} / \mathrm{v}$ Water: acetonitrile, $500 \mu \mathrm{L}$} \\
\hline \multicolumn{4}{|c|}{ Linear Gradient Program } \\
\hline Time (Min) & $\%$ Solvent- A & $\%$ Solvent- B & Curve \\
\hline 0.0 & 85 & 15 & - \\
\hline 1.5 & 70 & 30 & 6 \\
\hline 2.4 & 50 & 50 & 6 \\
\hline 2.5 & 85 & 15 & 6 \\
\hline 4.0 & 85 & 15 & 6 \\
\hline
\end{tabular}

Preparation of Standard and Sample Solutions

$0.22 \mu$ filtered HPLC grade water is used as diluent. Standard stock solution of pemetrexed is prepared by dissolving $40 \mathrm{mg}$ of working standard in diluent followed by further dilutions to meet $40 \mu \mathrm{g} / \mathrm{mL}$. Decrimped 5 vials containing lyophilized content of label claim equivalent to $100 \mathrm{mg}$ of pemetrexed, added 5 $\mathrm{mL}$ diluent to the vial. Wet the content, close with lid and completely dissolve the content by thorough vortexing and transfer the solution to $250 \mathrm{~mL}$ volumetric flask. Repeatedly rinse the vials 3 times with diluent and transfer the rinsing to the flask and make up $80 \%$ of final volume with diluent and thoroughly vortex for few minutes.

Dilute rest of volume with diluent to meet $0.4 \mathrm{mg} / \mathrm{mL}$ (Test stock). Final test concentration of $40 \mu \mathrm{g} / \mathrm{mL}$ is attained by diluting test stock with diluent. 


\section{METHOD VALIDATION}

\section{System Suitability and Precision}

System suitability is checked by injecting 5 repeated injections of standard solution. USP tailing factor (General chapter 611 ) of below $1.5, \%$ RSD of $<2 \%$ were obtained. A series of six individual samples were prepared and Repeatability (Precision) of the method is assessed by evaluating \% assay and \%RSD within acceptance criteria. The intermediate precision (Intra-Day) of the assay method is evaluated by different analyst on different day.

\section{Accuracy and Linearity}

The Accuracy of the assay method is evaluated using three concentration $50 \%, 100 \%, 150 \%$ to target test concentration and $\%$ added, $\%$ found and $\%$ recovered were evaluated. Keeping placebo weight constant, pemetrexed API is spiked at specified levels to attain range and to evaluate extraction efficiency. To establish Linearity of the assay method, a series of solutions at five concentration levels ranging from 25 to $200 \%$ of final test concentration (10 to $80 \mu \mathrm{g} / \mathrm{mL}$ ) were prepared from standard stock solution. The peak area versus concentration (in $\mu \mathrm{g} / \mathrm{mL}$ ) data for main peak (pemetrexed) is subjected to least-squares fit linear regression analysis and Slope, Y-Intercept, coefficient of correlation and bias at $100 \%$ response were evaluated.

\section{Specificity-Forced Degradation}

Specificity is the ability of an analytical method to measure the analyte response accurately in the presence of its potential impurities (Q2 (R1), 2005), which may be degradants or process related. The study also emphasizes the separation efficiency of the developed methods from placebo and other extraneous peaks, and evaluate the impact on quantification of peak of interest. In current study, the drug product is subjected for intentional degradation and is exposed for physical stress condition like thermal, humidity and photolysis. Test solution $(40 \mu \mathrm{g} / \mathrm{mL})$ were degraded by applying chemical stress conditions like acid, alkali and peroxide. Finalized stress conditions were applied for placebo and treated as same as stressed samples. Prior to loading in UPLC system for analysis, respective stressed samples were allowed to attain room temperature and subjected for neutralization. Refer to Table-3 for forced degradation details and stress conditions.

\section{Robustness}

To determine the robustness of the developed method, experimental conditions were deliberately altered to evaluate the impact of change in chromatographic conditions (Flow rate and column temperature). A change in flow rate of $\pm 10 \%$ i.e., 0.45 $\mathrm{mL} / \mathrm{min}$ and $0.55 \mathrm{~mL} / \mathrm{min}$ from actual flow rate and a change in \pm $5^{\circ} \mathrm{C}$ i.e., $35^{\circ} \mathrm{C}$ and $45^{\circ} \mathrm{C}$ of actual column temperature were studied to evaluate impact on system suitability.

\section{Solution Stability and Mobile Phase Stability}

The stability of solutions is determined by leaving solutions of the sample and standard in tightly capped volumetric flasks at room temperature from the day of preparation till 48 hours. The mobile phase prepared at the beginning of the study and set on UPLC system, is unaltered during the experiment and subsequently tested at an interval of 48 hours. Stability of mobile phase and solutions were determined by comparing with freshly prepared standard and difference in \% assay is calculated.

\section{RESULTS AND DISCUSSION}

\section{Method development Optimization}

As the pKa of pemetrexed is 3.34 (Strongest Acidic), and UV absorbance maxima at 230nm, Ortho phosphoric acid along with acetonitrile is chosen as mobile phase constituents (UV cut off $<205 \mathrm{~nm}$ ). Pemetrexed, being disodium salt and formulated with mannitol is freely soluble in water, and hence used as diluent for extraction. Initial trials were performed starting with a short linear gradient with Aquity $50 \times 2.1 \mathrm{~mm}, 1.7 \mu$ column and checked for reproducibility. Symmetric peak shape is not obtained due to early elution of peak and henceAquity100 x $2.1 \mathrm{~mm} 1.7 \mu$ column is selected and trails were performed to separate degradants generated during stress studies. With a linear gradient Time (in minutes)/\%B: $0.00 / 20,1.20 / 40,3.20 / 60,3.80 / 80$, $3.90 / 20,5.00 / 20$, at flow rate of $0.5 \mathrm{~mL} / \mathrm{min}$, USP resolution of $<1.9$ is obtained between main peak and major acid degradant. With flow rate of $0.3 \mathrm{~mL} / \mathrm{min}$, Time (in minutes)/\%B: $0.00 / 15$, $1.50 / 30,2.40 / 50,2.50 / 15,4.00 / 15$, satisfactory separation is achieved for main peak from acid and Oxidative degradant peaks with column temperature at $40^{\circ} \mathrm{C}$. With $3 \mu \mathrm{L}$ injection volume, symmetric peak shape with tailing factor of $<1.3$ and suitable area count is obtained for main peak at a concentration of $40 \mu \mathrm{g} / \mathrm{mL}$ in both standard and sample solutions. During analysis, carry over for main peak is noticed, which is rectified by using mix of $90: 10 \mathrm{v} / \mathrm{v}$ Water: ACN as weak needle, set at $500 \mu \mathrm{L}$ and mix of 90:10 ACN: Water v/v as Strong needle, set at $500 \mu \mathrm{L}$.

\section{Specificity-Forced degradation}

All forced stressed samples were analyzed as per UPLC conditions (Section 2.2 and 2.3) using PDA detector to ensure spectral homogeneity and peak purity. Potential degradation of pemetrexed is observed in acid, peroxide stress conditions. $>10 \%$ degradation is achieved in acid stress, where single major degradant at RT $2.134 \mathrm{~min}$ is noticed. $>15 \%$ degradation is achieved in peroxide stress, where two major degradants were noticed at RT 1.015 and $1.331 \mathrm{~min}$. Although 5\% degradation is achieved in alkali stress, no impact on peak purity is observed. No significant degradation is obtained with rest of the stress conditions, like thermal, photolytic and water hydrolysis. Blank and stressed placebo doesn't show any interference at retention time of main peak. Gradient is extended for 5 minutes to wash out any degradants (if any), and all peaks were eluted below 2.5 minutes. 
Table 2A: System suitability results.

\begin{tabular}{lccc}
\hline System suitability & $\begin{array}{c}\text { Retention time } \\
\text { in } \min (\mathbf{n}=\mathbf{5}) *\end{array}$ & $\begin{array}{c}\text { USP Tailing } \\
(\mathbf{n}=\mathbf{5}) *\end{array}$ & $\begin{array}{c}\text { \% RSD } \\
(\mathbf{n}=\mathbf{5}) *\end{array}$ \\
\hline & & & \\
Method Precision & 1.55 & 1.24 & 0.6 \\
Inter-Precision & 1.52 & 1.23 & 0.4 \\
\hline
\end{tabular}

Table 2B: Precision results.

\begin{tabular}{lcccccccc}
\hline Method Precision & Sample-1 & Sample-2 & Sample-3 & Sample-4 & Sample-5 & Sample-6 & Mean ** & \% RSD $* *$ \\
\%Assay & 101.0 & 100.9 & 100.5 & 100.3 & 100.7 & 100.4 & 100.6 & 0.28 \\
Inter-Precision & Sample-1 & Sample-2 & Sample-3 & Sample-4 & Sample-5 & Sample-6 & Mean & $\%$ RSD \\
\%Assay & 100.1 & 99.7 & 101.1 & 100.9 & 99.9 & 100.3 & 100.3 & 0.56 \\
\hline
\end{tabular}

*For Standard, ** Acceptance Limits: Assay $=97 \%$ to $103 \%$ for $\mathrm{n}=6$ test preparations and $\% \mathrm{RSD} \leq 2.0$

Solution Stability: For Standard-Similarity Factor: New vs 48 Hours Standard: 1.01 (limit: 0.98 to 1.02).

For sample \% Difference: Initial vs 48 Hours Sample: 0.51 (Limit: $\pm 2.0 \%$ ).

Mobile Phase Stability: After 48 Hours : \% RSD for standard ( $\mathrm{n}=5)$ : 0.7, USP Tailing: 1.22,

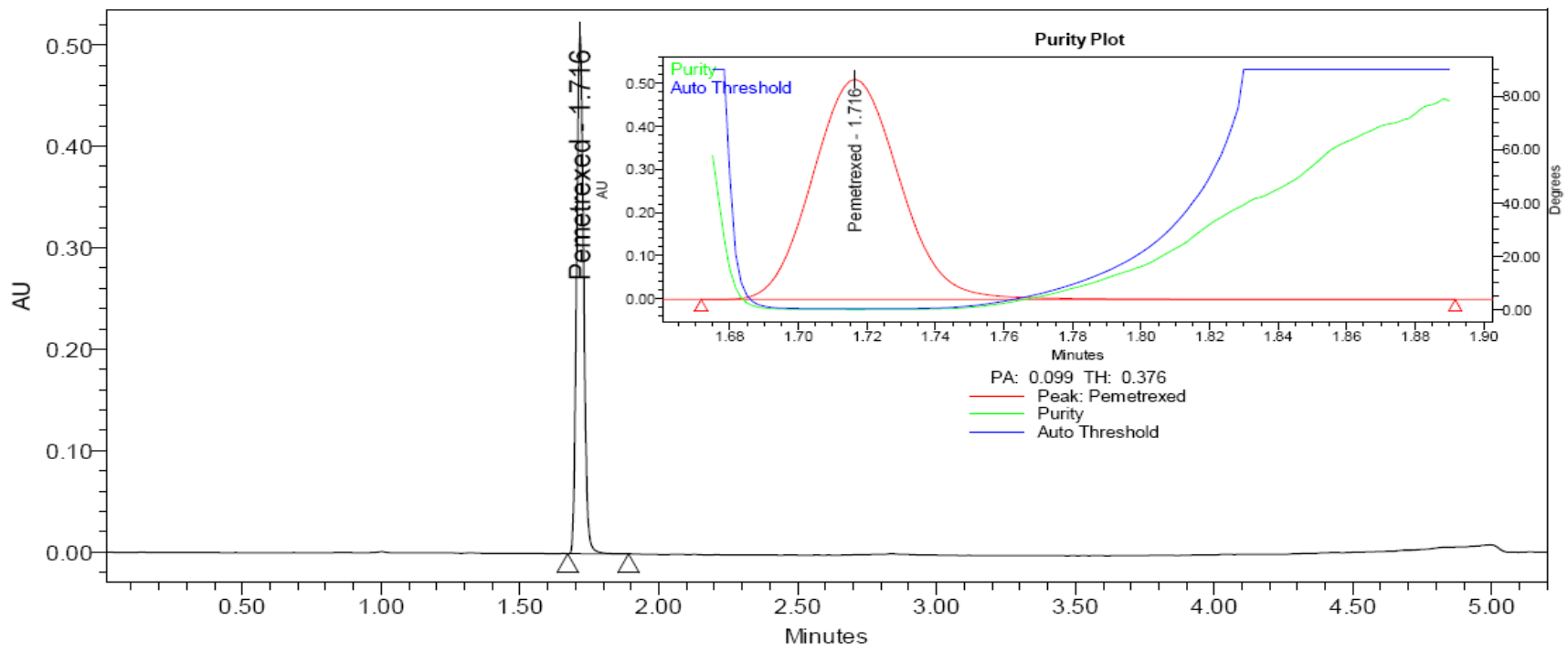

Fig. 2A: Typical Chromatogram of Unstressed Sample.

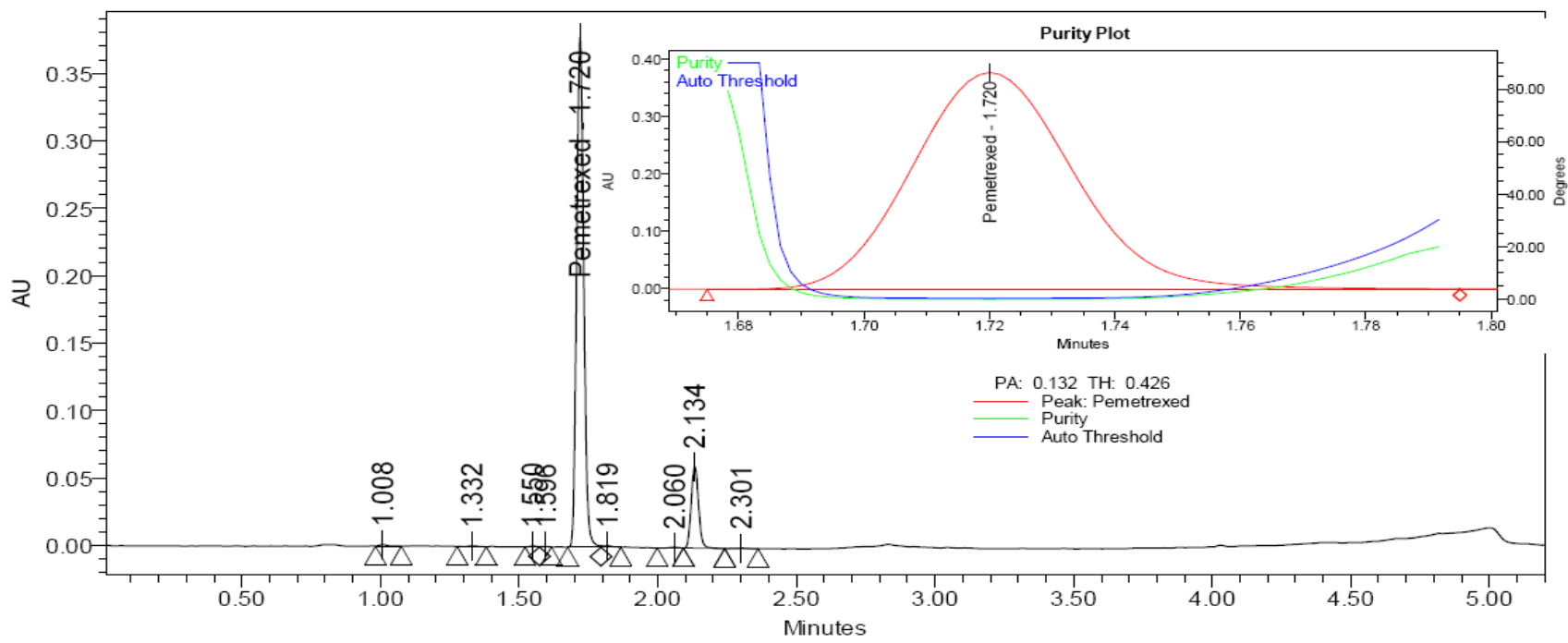

Fig. 2B: Typical Chromatogram of Acid Stressed sample. 


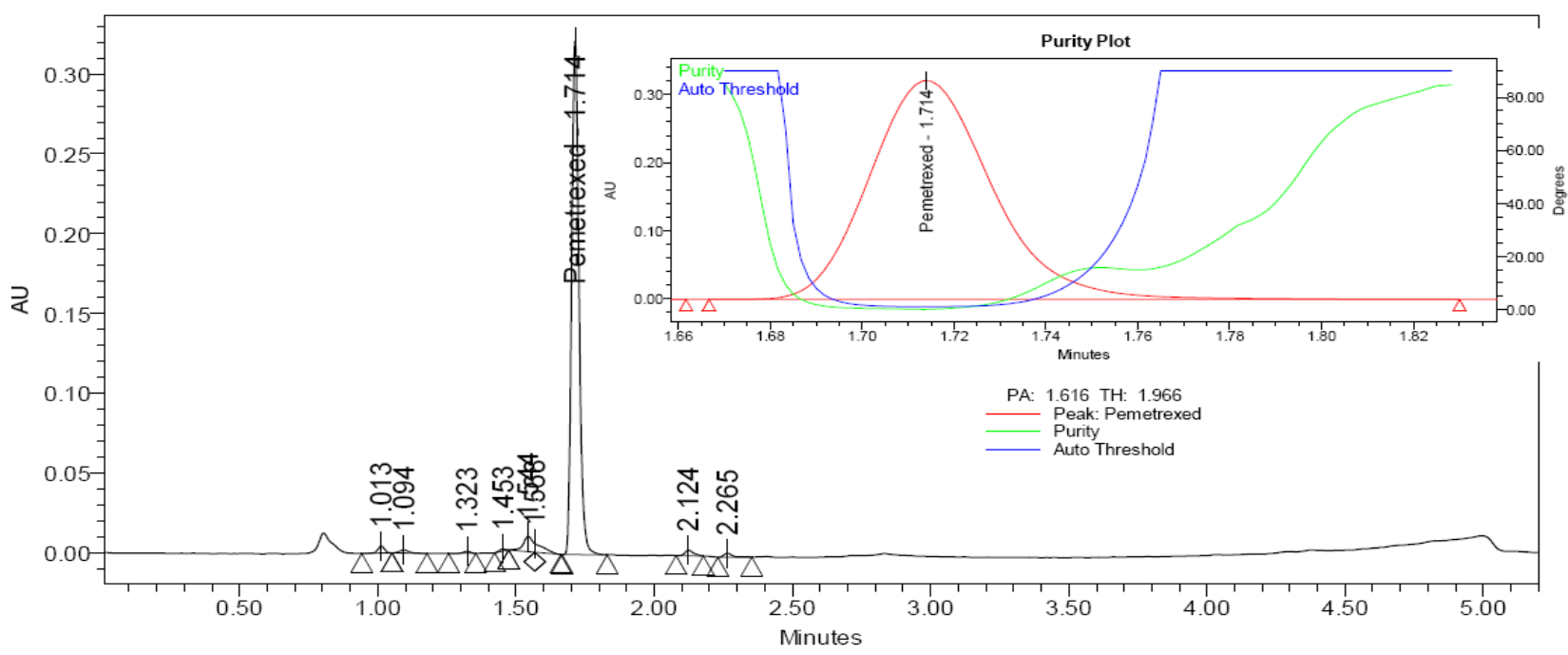

Fig. 2C: Typical Chromatogram of Alkali Stressed sample.

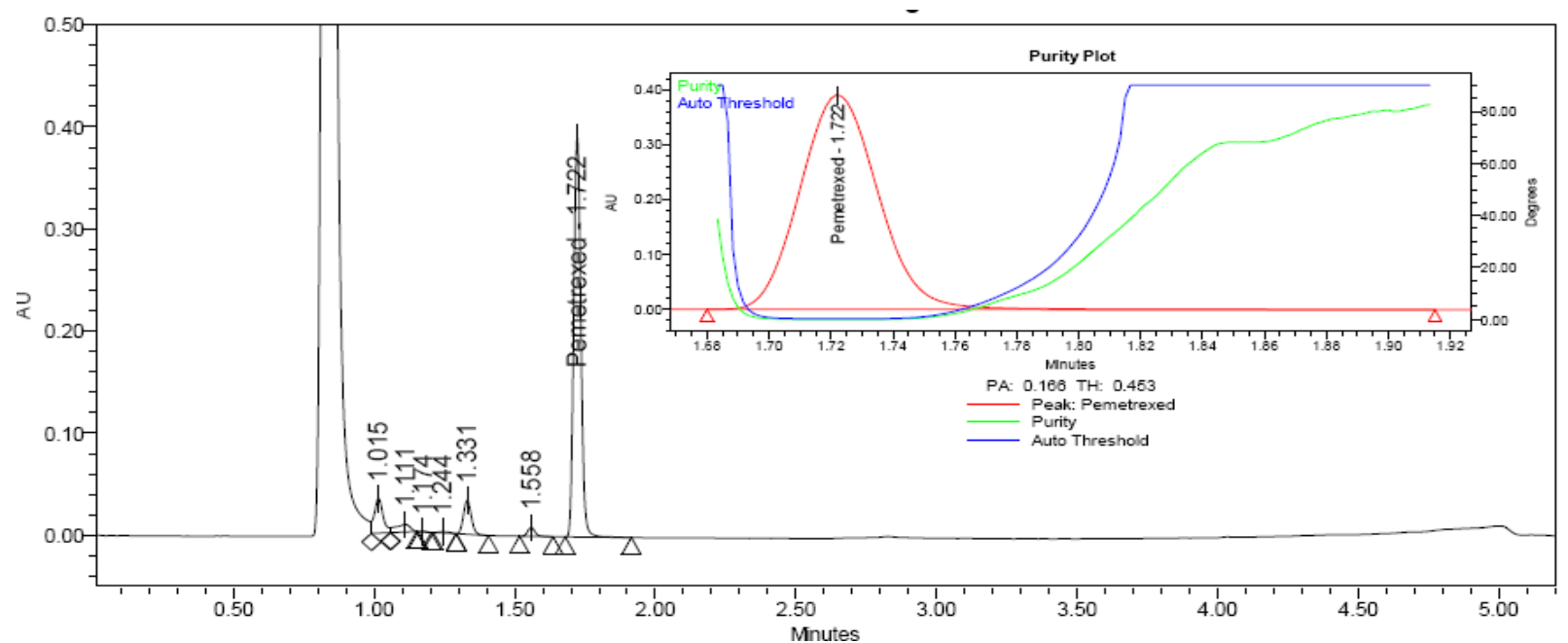

Fig. 2D: Typical Chromatogram of Peroxide Stressed sample.

Table 3: Results of Stress Studies.

\begin{tabular}{|c|c|c|c|c|c|c|}
\hline Stress Condition & Stress Conditions & $\begin{array}{c}\% \\
\text { Degraded }^{* *}\end{array}$ & $\begin{array}{l}\text { Purity } \\
\text { Angle* }\end{array}$ & $\begin{array}{c}\text { Purity } \\
\text { Threshold* }\end{array}$ & $\begin{array}{l}\text { Purity } \\
\text { Flag* }\end{array}$ & $\begin{array}{l}\text { Purity } \\
\text { Error* }\end{array}$ \\
\hline Unstressed Sample & Not applicable & 0.00 & 0.099 & 0.376 & No & No \\
\hline Acid Stressed Sample & $1 \mathrm{~N} \mathrm{HCl}, 60^{\circ} \mathrm{C}$ in water bath, 3 hours & 15.32 & 0.132 & 0.426 & No & No \\
\hline Alkali Stressed Sample & $1 \mathrm{~N} \mathrm{NaOH}, 60^{\circ} \mathrm{C}$ in water bath, 3 hours & 5.93 & 1.616 & 1.966 & No & No \\
\hline Humidity Stressed Sample & $90 \% \mathrm{RH} / 25^{\circ} \mathrm{C}$ Saturated $\mathrm{KNO}_{3}$ & 0.18 & 0.191 & 0.463 & No & No \\
\hline Photo Stressed Sample & 1.2 M Lux hours-ICH & 0.21 & 0.107 & 0.398 & No & No \\
\hline Hydrolysis Stressed Sample & Water, $60^{\circ} \mathrm{C}$ in water bath, 3 hours & 1.76 & 0.109 & 0.370 & No & No \\
\hline Thermal Stressed Sample & $105^{\circ} \mathrm{C}$ for 24 hours & 0.00 & 0.100 & 0.382 & No & No \\
\hline
\end{tabular}

(*) For peak purity as per Waters Empower software: Purity angle must be less than purity threshold, and must have no purity flag and purity error. (**) $\%$ Degraded $=\%$ assay of unstressed sample - \% Assay of stressed sample 
All samples were screened by PDA from UV 200 to 400 $\mathrm{nm}$, where no extra peaks were noticed. Peak purity is assessed by ensuring peak purity < purity threshold with no purity flag for all stressed and unstressed samples. Spectral purity of the peak and no impact of assay of pemetrexed under the influence of optimized stress conditions and potential degradants, confirm the stabilityindicating capability of the newly developed method. Refer Table3 and figure $2 \mathrm{~A}$ to $2 \mathrm{D}$ for chromatograms of stress studies.

\section{System suitability and Precision}

System suitability parameter is passed and is within acceptable limits. The \% RSD of assay during the method's precision and intra-day study is 0.28 and 0.56 and results found reproducible, hence forth conforming the suitability and repeatability of the method. Refer Table-2A and $2 \mathrm{~B}$.

\section{Accuracy and Linearity}

The mean recovery of pemetrexed at three levels $50 \%$, $100 \%$ and $150 \%$ is ranged from $99.89 \%$ to $100.76 \%$ with a $\%$ RSD below $2 \%$ per triplicate sample preparation for each level. Linearity of the detector response verses concentration of analyte is attained over the established calibration ranges tested between 10 to $80 \mu \mathrm{g} / \mathrm{mL}$ and correlation coefficient obtained is greater than 0.999 and a bias of $1.43 \%$ for Pemetrexed peak. From results, it is evident that the method covers a satisfactory range towards accuracy and linearity as per current validation practices. Refer Table-4A and 4B.

Table 4A: Results of Accuracy.

\begin{tabular}{lccccc}
\hline Sample name & $\begin{array}{c}\text { Added } \\
(\boldsymbol{\mu g} / \mathbf{m L})\end{array}$ & $\begin{array}{c}\text { Found } \\
(\boldsymbol{\mu g} / \mathbf{m L})\end{array}$ & $\begin{array}{c}\text { \% } \\
\text { Recovery } \\
\text { Assay* }\end{array}$ & $\begin{array}{c}\text { Average } \\
\mathbf{n = 3}\end{array}$ & $\begin{array}{c}\text { RSD } \\
\mathbf{n = 3}\end{array}$ \\
\hline Accuracy 50\% Spl-1 & 19.9200 & 20.0650 & 100.73 & & \\
Accuracy 50\% Spl-2 & 20.0400 & 20.1240 & 100.42 & 100.34 & 0.42 \\
Accuracy 50\% Spl-3 & 20.1200 & 20.0971 & 99.89 & & \\
Accuracy 100\% Spl-1 & 40.0800 & 40.0734 & 99.98 & & \\
Accuracy 100\% Spl-2 & 40.8400 & 40.9535 & 100.28 & 100.29 & 0.32 \\
Accuracy 100\% Spl-3 & 40.3200 & 40.5700 & 100.62 & & \\
Accuracy 150\% Spl-1 & 60.1200 & 60.1484 & 100.05 & & \\
Accuracy 150\% Spl-2 & 59.9200 & 60.2396 & 100.53 & 100.45 & 0.36 \\
Accuracy 150\% Spl-3 & 60.2000 & 60.6563 & 100.76 & & \\
\hline
\end{tabular}

$* \%$ Recovered and average of $n=3$ per each level must be within $97 \%$ to $103 \%$, $\%$ RSD must be $\leq 2$.

Table 4B: Results of Linearity.

\begin{tabular}{lcccc}
\hline Linearity Range & Slope & y-intercept & r * & Bias 100\% \\
\hline 10 to $80 \mu \mathrm{g} / \mathrm{mL}$ & 22237.22 & 13005.648 & 0.99966 & 1.43 \\
\hline * Coefficient of Correlation: Limit: $>0.999$, Bias at $100 \%$ & response: \\
within $\pm 2 \%$
\end{tabular}

\section{Solution Stability and Mobile Phase Stability}

Mobile phase found stable and is visually clear with no precipitation or turbidity and System suitability parameters were passed over a period of 48 hours. Similarity factor and \% assay difference of Standard and test solutions stability results were within $\pm 1 \%$ till 48 hours, when compared with initial \% assay. Refer Table-2B.

\section{Robustness}

Under variable chromatographic conditions (flow rate, column temperature), System suitability parameters were passed and found within the acceptance criteria. This proves that the newly developed method is robust and can withstand deliberate changes in chromatographic conditions. Refer Table-5.

Table 5: Results of Robustness.

\begin{tabular}{lccc}
\hline Parameter & RT $^{*}$ & $\begin{array}{c}\text { \% RSD } \\
(\mathbf{n}=5) * *\end{array}$ & $\begin{array}{c}\text { USP } \\
\text { Tailing }\end{array}$ \\
\hline $0.45 \mathrm{ml} / \mathrm{min}$ flow rate & 1.732 & 0.29 & 1.25 \\
$0.55 \mathrm{ml} / \mathrm{min}$ flow rate & 1.417 & 0.47 & 1.24 \\
$35^{\circ} \mathrm{C}$ Column temperature & 1.573 & 0.36 & 1.25 \\
$45^{\circ} \mathrm{C}$ Column temperature & 1.496 & 0.73 & 1.24 \\
\hline
\end{tabular}

* retention time in minutes, ** For standard peak

\section{CONCLUSIONS}

Recent advancement in chromatography techniques and improved understanding on chemistry, degradation behavior and stability of drug substances and drug products made regulatory authorities and $\mathrm{ICH}$ guidelines to raise concerns over developing and validating stability-indicating LC methods to evaluate quality through stability testing (ICH Q2 (R1) 2005). The newly developed, rapid simple linear gradient stability indicating RP UPLC method with shortest runtime of 4.0 minutes for determining assay of pemetrexed from parenteral formulation in presence of forced degradation products is specific, precise, accurate, linear and robust. Reproducible and smooth baseline is achieved throughout the work and issues due to Carry over which generally rise during analysis were well resolved. Satisfactory results were obtained from validation of the method as per ICH. This stability-indicating method can be implemented to support analysis of developmental, lab-scale, QC-stability testing and production samples of pemetrexed disodium parenteral formulation.

\section{ACKNOWLEDGEMENT}

The author wish to thank the Department of Biochemistry, Nagarjuna University for providing facilities to conduct this work. Inputs and supports from co-workers and colleagues were well appreciated. Author bears no conflict of interest towards publication of this work.

\section{Financial support and sponsorship: Nil.}

Conflict of Interests: There are no conflicts of interest. 


\section{REFERENCES}

Adjei AA, Pemetrexed (Alimta): a novel multitargeted antifolate agent. Expert Rev Anticancer Ther, 2003; 3(2):145-56. DOI: 10.1586/14737140.3.2.145 2014.

Banu T, Varanasi MB, Khan MMA, Sharma JVC, Teja BB, Kumar VS, Habibuddin M, Validated reverse phase HPLC method for the determination of pemetrexed disodium in pharmaceutical dosage forms. Oriental J Chem, 2010; 1325-1332.

Hanauske AR, Chen V, Paoletti P, Niyikiza C, Pemetrexed disodium: A novel antifolate clinically active against multiple solid tumors. The Oncologist, 2001; 6(4):363-73.

http://www.rxlist.com/alimta-drug.htm [Accessed on 02-03-

2017].

International Conference on Harmonization. Guideline on Validation of Analytical Procedures. 2005; Q2 (R1).

Julian R, Ping Yang, Stephen DC, Steven ES, Alex A, NonSmall Cell Lung Cancer: Epidemiology, Risk Factors, Treatment, and Survivorship. Mayo ClinProc, 2008; 83(5):584-594, DOI: 10.4065/83.5.584.

Li Wang, Yan Sun S, Jian J, Chuan Li, Determination of pemetrexed in Sprague-Dawley rats by LC/MS/MS and study on its pharmacokinetics. Asian J Pharmaco dynamics and Pharmacokinetics, 2006; 6(3):240-246.

Meesters RJW, Cornelissen R, Klaveren RJV, Jonge R, Boer E, Lindemans J, Luider TM, A new ultrafast and high throughput mass spectrometric approach for the therapeutic drug monitoring of the multitargeted antifolate pemetrexed in plasma from lung cancer patients. Anal BioanalChem, 2010; 398, 2943-2948.

Mazzeo JR, Neue UV, Marianna K, Plumb RS, Advancing LC Performance with Smaller Particles and Higher Pressure. Anal Chem, 2005; 77 (23) 460 A-467 A, DOI: 10.1021/ac053516f.

Nguyen DT, Guillarme D, Rudaz S, Veuthey JL, Fast Analysis in Liquid Chromatography Using Small Particle Size and High Pressure. J. Sep. Sci, 2006; 29, 1836-1848.

Pathi PJ, Khan PS, Reddy PR, Raju NA, Visible spectrophotometric estimation of pemetrexed disodium in pharmaceutical formulations. J Pharm Res, 2011; 4, 524-525.

Pascale T, Fabrice B, Celine M, and Laurent G, Pemetrexed for advanced stage nonsquamous non-small cell lung cancer: latest evidence about its extended use and outcomes. Ther Adv Med Oncol, 2016; 8(3): 198-208. DOI: $10.1177 / 1758834016644155$.

Pharmeuropa, European Directorate for the Quality of Medicines \& Health Care, Council of Europe, France, 2008; 20: 264.

Rondelot G, Serrurier C, Vigneron J, Zenier H, May I, Demore B, Stability of Pemetrexed $25 \mathrm{mg} / \mathrm{mL}$ in a glass vial and $5 \mathrm{mg} / \mathrm{mL}$ stored in a PVC container after storage for one month at $2-8{ }^{\circ} \mathrm{C}$. EJHP Science, $2007 ; 13,14-16$
Roland JWM, Robin C, Rob J. van K, Robert J, Ethan den B, Lindemans J, Theo Luider M., A new ultrafast and high-throughput mass spectrometric approach for the therapeutic drug monitoring of the multitargeted anti-folate pemetrexed in plasma from lung cancer patients. Anal Bioanal Chem, 2010; 398(7-8): 2943-2948. DOI: 10.1007/s00216-0104192-8.

Rivory LP, Clarke SJ, Boyer, M, Bishop JF, Highly sensitive analysis of the antifolate pemetrexed sodium: A new cancer agent in human plasma and urine by High Performance Liquid Chromatography. J Chromatography B: Bio Med SciAppl, 2001; 765, 135-140.

Russo R, Guillarme D, Nguyen, T-T. D, Bicchi C, Rudaz. S, Veuthey, J. L, Pharmaceutical Applications on Columns Packed with Sub2 mm Particles. J. Chromatogr. Sci, 2008; 46, 199-208.

Saravanan G, Suryanarayana MV, Jadhav J, Ravikumar M, Someswararao N, Acharyulu PVR ,A Stability-Indicating LC Assay Method for Pemetrexed Disodium. Chromatographia, 2007; 66, Sept (No. 5/6). DOI: 10.1365/s10337-007-0309-4 0009-5893/07/09.

United States Pharmacopeia. The United States Pharmacopeial Convention, Rockville, MD, 2011; 34, 2040.

Villiers AD, Lestremau F, Szucs R, Gelebart S, David F, Sandra P, Evaluation of Ultra Performance Liquid Chromatography: Par I. Possibilities and Limitations. J. Chromatogr. A, 2006; 1127, 60-69.

Wren SAC, Tchelitcheff P. Use of Ultra-Performance Liquid Chromatography in Pharmaceutical Development. J. Chromatogr. A 2006; 1119, 140-146.

Zhang Y, Trissel LA, Oncology: Physical and chemical stability of pemetrexed in infusion solutions, Ann Pharmacother, 2006; 40, 1082 1085 .

\section{How to cite this article:}

Galla VK, Archana V, Jinka R. A new rapid Stability indicating RP-PDA-UPLC method for the estimation of Assay of Pemetrexed disodium-An anti-Lung cancer drug from lyophilized parenteral formulation. J App Pharm Sci, 2017; 7 (10): 131-137. 